\title{
La vacunación para hepatitis B en la infancia previene infecciones crónicas en la adolescencia
}

Observational study of vaccine efficacy 14 years after trial of hepatitis B vaccination in Gambian children. Whittle $\mathrm{H}$, Jaffar $\mathrm{S}$, Wansbrough M et al. BMJ 2002; 325:569-573.

\section{Objetivo}

Determinar la eficacia de la vacuna de hepatitis B contra la infección y portación crónica.

Diseño

Estudio serológico de 14 años de seguimiento.

Lugar

Dos poblaciones en Gambia.

\section{Pacientes}

Niños y adolescentes que recibieron la vacuna para la hepatitis $B$ en la infancia y niñez temprana: 322 de $1-5$ años, 225 de 5-9 años, 220 de 10-14 años y 175 de 15-19 años.

Intervención

Se vacunó desde 1984 a todos los niños menores de 5 años y a los recién nacidos seronegativos para el virus de la hepatitis $B$ (VHB). Los primeros fueron aleatorizados para recibir la vacuna derivada de plasma (H-B-Vax, Merck Sharpe \& Dohme) según uno de los 3 regímenes;grupo 1:3 dosis de $2 \mathrm{mg}$ intradérmica; grupo 2: $2 \mathrm{mg}$ intradérmica mas 2 dosis de $20 \mathrm{mg}$ intramuscular y grupo 3: 3 dosis de $20 \mathrm{mg}$ intramuscular.

\section{Medición de resultados principales}

Se determinó la concentración de anticuerpos anti-HBsAg 2 meses post-vacunación.El anti-HBsAg y anti-HBc y HbsAg fueron realizados en 1984, 1989, 1993 y 1998, estableciendo la proporción de infectados y portadores crónicos.

\section{Resultados}

Al año 1998, habían sido vacunados 1.041 jóvenes $(833<15$ años y $208 \geq 15$ años).Se excluyeron 29 menores de un año y 23 que habían recibido dosis insuficiente de vacuna. A su vez 64 rehusaron participar, 33 murieron y 36 no pudieron ser rastreados, quedando solo 856 jóvenes que fueron seguidos por una mediana de 13,8 años. La eficacia de la vacuna contra la portación crónica del virus fue de $94 \%$ y no varió con las poblaciones o edades (Tabla). La eficacia contra la infección fue de $82 \%$ (78 a $85 \%$ ) la cual no varió entre las poblaciones, aunque si varió por grupo erario ya que fue significativamente menor en el grupo $\geq 15$ años:65\% $(p<0,001)$. El pico de respuesta de anticuerpos decayó en forma exponencial a lo largo del el tiempo. El tiempo desde la vacunación y el bajo pico inicial de respuesta de anticuerpos fueron los factores de riesgo más poderosos de infección ( $\mathrm{P}<0,001$ para ambos). El bajo pico de respuesta de anticuerpos también parece ser un factor de riesgo para la portación crónica de HVB: OR 95 (19 a 466).

Tabla. Eficacia de la vacuna contra la portación crónica y la infección según grupo etario

\begin{tabular}{|c|c|c|c|c|}
\hline & \multicolumn{2}{|c|}{ Portación crónica } & \multicolumn{2}{|c|}{ Infección } \\
\hline & $\begin{array}{l}\text { No portadores } \\
\text { vacunados v } \\
\text { controles }\end{array}$ & $\begin{array}{c}\text { Eficacia (\%) } \\
\text { (IC 95\%) }\end{array}$ & $\begin{array}{c}\text { № infectados } \\
\text { vacunados v } \\
\text { controles }\end{array}$ & $\begin{array}{c}\text { Eficacia }(\%) \\
\text { (IC 95\%) }\end{array}$ \\
\hline Global & $10 / 855$ v 191/931 & 94 (89 a 97) & $102 / 847$ v 564/929 & $80(76$ a 84$)$ \\
\hline$>5$ años & $3 / 235 \vee 68 / 354$ & 93 (79 a 98) & $14 / 232$ v 140/354 & 85 (74 a 91) \\
\hline 5-9 años & $0 / 225$ v 66/309 & 100 & $10 / 224$ v 309/509 & 93 (85 a 96$)$ \\
\hline 10-14 años & $2 / 220$ 39/191 & 96 (82 a 99) & $33 / 220$ v $156 / 190$ & 82 (75 a 87) \\
\hline$\geq 15$ años & $5 / 175$ v $18 / 77$ & 88 (68 a 95$)$ & $53 / 171$ $68 / 76$ & 65 (56 a 73) \\
\hline
\end{tabular}

\section{Conclusiones}

Los niños vacunados en la infancia tienen mayor riesgo de infección por virus de la hepatitis $\mathrm{B}$ en la adolescencia tardía.

El riesgo de portación crónica luego de la exposición sexual se incrementa, y se necesita ampliar los estudios para evaluar si las dosis de refuerzo en el inicio de la actividad sexual serán necesarias.

\section{Palabras claves:}

Prevención, vacuna, hepatitis B, refuerzo, adolescencia.

Fuente de financiamiento:Medical Research Council (RU) y Merck Sharpe \& Dohme (EEUU).

\section{Comentario}

La infección crónica por el VHB es una de las principales causas de muerte por cáncer, una cuarta parte de los 60 millones de portadores mueren por carcinoma hepatocelular primario o por cirrosis del hígado. ${ }^{1,2}$ El programa de Gambia se comenzó en 1986, como parte de un trabajo para probar la eficacia de la vacunación contra el VHB en la prevención del carcinoma hepatocelular. A 14 años del inicio del programa de vacunación, se estableció que la eficacia de la vacuna contra la portación crónica de VHB se mantiene, aun con una baja concentración de anticuerpos.

El rol de los refuerzos naturales en el mantenimiento de la inmunidad en grupos altamente endémicos no esta claro, pero de existir, seria la exposición sexual de la población joven, la que favorecería el mantenimiento de la inmunidad tanto celular como humoral.Al presente hay insuficientes datos como para decidir si una dosis de refuerzo seria útil en los adolescentes en áreas de alta endemicidad donde el $15 \%$ de las parejas sexuales pueden ser portadores crónicos. ${ }^{3.4}$ En áreas de baja endemicidad, los adolescentes vacunados en la infancia pueden perder la inmunidad a causa de la pérdida de exposición y podría ser necesaria una dosis de refuerzo.En este contexto podría ser más conveniente aplicar la vacuna en la adolescencia.
Los nuevos casos y los portadores crónicos, estuvieron clara y fuertemente relacionados a los bajos picos de concentración de anticuerpos para VHB; así, la mitad de los niños que no desarrollaron concentraciones detectables de anticuerpos se infectaron y de estos, cerca de al mitad se volvieron portadores crónicos no pudiéndose determinar que factores serían los mas importantes en la aparición de nuevos casos y de portadores crónicos.

Pocos estudios en infantes o niños jóvenes vacunados contra VHB fueron más largos que 10 años. Estos estudios demuestran que en países donde la infección es endémica, la eficacia de la vacuna contra la infección disminuye con el tiempo, pero la eficacia contra la infección crónica permanece alta por al menos 14 años. Esto es consistente con un estudio Chino de 15 años de seguimiento, mostrando la persistencia de la memoria inmunológica luego de la desaparición de la respuesta humoral de anticuerpos. ${ }^{5}$ El presente estudio a pesar de ser pequeño y tener muchas pérdidas de pacientes, fue considerado para un consenso que estableció la falta de necesidad de revacunar luego de los 15 años de la primovacunación. ${ }^{6}$ Sin embargo, todavía es necesario realizar un estudio mayor para evaluar la eficacia en adolescentes, antes de concluir definitivamente que una dosis de refuerzo no es necesaria antes del inicio de actividad sexual.

\section{Dr. Raúl Guillermo Espinosa [ Unidad de Medicina Familiar y Preventiva del Hospital Italiano de Buenos Aires ] \\ Dr. Agustín Ciapponi [ Unidad de Medicina Familiar y Preventiva del Hospital Italiano de Buenos Aires ]}

\section{Referencias}

1. World Health Organization. Prevention of primary liver cell cancer. Report on a meeting of a WHO scientific group.Lancet 1983;1:463-65

2. Kane MA, Clements J, Hu D. Hepatitis B. In: Jamison OT, Mosley WH, Meashman AR, Bobadilla J. Eds.Disease control priorities in developing countries.A World Bank Book. New York:Oxford University Press, 1003:321-30.

3. Whittle HC, Bradley AK, McLaughlan K, Shenton F, Howard CR, Zuckerman AJ, et al.Hepatitis B infection in two Gambian villages.Lancet 1983;i:1203-6.

4. Vall-Mayans M, Hall AJ, Inskip HM, Chotard J, Lindsay SW, Coromina E, et al.Risk factors for transmission of hepatitis B virus a Gambian children.Lancet 1990; $336: 1107-9$.

5. Liao SS, Li RC, Li H, Yang JY, Aeng XJ, Gong J, et al. Long-term efficacy of plasma derived vaccine: a 15-year follow-up study among Chinese children.Vaccine 1999; 17:2661-2666

6. European Consensus Group on Hepatitis B Immunity Are booster immunisations needed for lifelong hepatitis B immunity? Lancet 2000:355:561-565 